\title{
AVALIAÇÃO ECONÔMICA DE UM SISTEMA DE TRAMENTO DE RESÍDUOS DA SUINOCULTURA CONTENDO BIODIGESTORES TUBULARES
}

\author{
Célio Moreira Ricardo ${ }^{1}$, Alessandro Torres Campos$^{2}$, Diego Bedin Marin ${ }^{3}$, Alessandro Vieira Veloso ${ }^{4} \&$ Matheus Campos Mattioli $^{5}$ \\ 1 - Mestre em Engenharia Agrícola pela Universidade Federal de Lavras. E-mail: celio.moreira@engflextecnologia.com.br) \\ 2 - Professor Associado do Departamento de Engenharia da Universidade Federal de Lavras. E-mail: campos@deg.ufla.br \\ 3 - Doutorando do Programa de Pós-Graduação em Engenharia Agrícola da Universidade Federal de Lavras. E-mail: db.marin@hotmail.com \\ 4 - Professor Adjunto do Departamento de Engenharia da Universidade Federal de Lavras. E-mail: alessandro.veloso@deg.ufla.br \\ 5 - Doutorando do Programa de Pós-Graduação em Engenharia Agrícola da Universidade Federal de Lavras. E-mail: mattioli-cmatheus@hotmail.com
}

\section{Palavras-chave:}

Biodigestão anaeróbia construções rurais efluentes suinícolas impacto ambiental manejo de resíduos viabilidade econômica.

\section{RESUMO}

Nos últimos anos, a suinocultura tem causado grande ônus ambiental devido ao manejo incorreto dos resíduos. Contudo, o processo de biodigestão anaeróbia, por meio de biodigestores, tem se constituído uma tecnologia interessante quando se busca solução para os problemas ambientais, que são evidenciados nas águas, ar e solo, além de produzir biogás e biofertilizante para as áreas rurais. No presente trabalho, objetivou-se desenvolver uma análise econômica de um sistema de tratamento de resíduos da suinocultura, contendo biodigestores tubulares, bem como descrever a simulação de um cenário a partir da venda de energia elétrica para as concessionárias de distribuição. Na metodologia utilizada para a avaliação econômica, compuseram-se o valor presente líquido, a taxa interna de retorno, a relação benefício custo e o período de recuperação do capital simples e econômico. $\mathrm{Na}$ análise econômica, observou-se que o valor presente líquido foi de $\mathrm{R} \$ 17.210,51$. O percentual estimado para taxa interna de retorno é de 7\% a.a., que foi $1 \%$ superior à taxa de atratividade mínima. A relação benefício custo, estimada em 1,42, é considerada alta para este tipo de investimento, representando uma eficiência econômica de $42 \%$. O período de recuperação do capital investido simples foi de sete anos e o período de recuperação do capital econômico foi estimado em oito anos, tempo compatível para o nível de investimento. A avaliação econômica do sistema permitiu concluir que o projeto é economicamente atrativo e a possibilidade da venda de eletricidade para a concessionária de energia cria um cenário favorável nos aspectos econômicos, ambientais, sociais e agronômicos.

\section{Keywords:}

Anaerobic biodigestion economic viability environmental impact rural buildings swine effluents waste management

\section{ECONOMIC EVALUATION OF TUBULAR BIODIGESTERS FOR THE TREATMENT OF SWINE PRODUCTION WASTES}

\section{ABSTRACT}

In recent years, the swine farming has caused huge environmental issues due to the incorrect management of wastes. However, the process of anaerobic biodigestion, through biodigestors, has become an appealing technology when searching for solutions to environmental problems, which are evident in the water, air and soil, as well as producing biogas and biofertilizer for rural areas. The aim of the present study was to develop an economic analysis of a treatment system for swine wastes by tubular biodigesters and to describe the simulation of a scenario from the sale of electricity to distribution companies. The methods used for the economic evaluation were the net current value, internal rate of return, benefit-cost ratio, and the time for recovering the invested and the economic capital. According to the economical analysis it could be seem that the net current value was $\mathrm{R} \$ 11.413,56$. The estimated percentage for internal rate of return was $7 \%$ per year, which was $1 \%$ above the minimum attractiveness rate. The estimated benefitcost ratio was 1.42 , representing an economical efficiency of $42 \%$, which can be considered high regarding this kind of investment. The time for recovering the invested capital was seven years and the time for recovering the economic capital was eight years, which is a compatible time considering the investment level. Through the economical evaluation of the system, it can be concluded that the project is economically attractive and the possibility of selling electricity to power distribution companies creates a propitious scenario in economical, environmental, social and agronomical aspects. 


\section{INTRODUÇÃO}

O atual desempenho da suinocultura se deve às grandes transformações ocorridas no setor com a migração do modelo de produção para sistemas cada vez mais intensivos, os quais concentram os rebanhos em unidades confinadas, contribuindo para uma maior eficiência da produção e fornecimento de produtos de qualidade (HIGARASHI et al., 2008).

Entretanto, se por um lado o aumento no nível dos confinamentos proporcionou alavancar saltos de produtividade, por outro lado, nas últimas décadas, mesmo com toda a sua relevância, a suinocultura tem despertado a preocupação ambiental da sociedade devido ao grande impacto causado aos recursos naturais pela elevada quantidade de resíduos gerados na atividade (KUNZ et al., 2009b; SOUZA et al., 2009; SOUZA et al., 2008).

Dessa forma, o grande desafio para a cadeia produtiva de suínos éa exigência da sustentabilidade ambiental, nas regiões de produção intensiva, pois, de um lado, existe a pressão pelo aumento do nível dos confinamentos e da produtividade e, de outro, a pressão para que este aumento não afete o meio ambiente (KUNZ et al., 2005).

Diante disso, fica evidente que o manejo e o tratamento de resíduos é parte integrante do sistema de produção de suínos (OLIVEIRA et al., 2007). Dessa forma, conforme descreveram Kunz et al. (2009a), as estratégias para o tratamento desses resíduos se baseiam em vários tipos de processos físicos, químicos e biológicos, que são capazes de reduzir o seu potencial poluidor, convertendoos em produtos, como o fertilizante orgânico e o biogás.

Neste contexto, uma das alternativas que contribuem para o saneamento rural e, ao mesmo tempo, para geração de energia renovável é a tecnologia de biodigestão anaeróbia de resíduos provenientes da suinocultura, por meio de biodigestores que possibilitam a geração de dois produtos valiosos: o biogás e o adubo orgânico (ESPERANCINI et al., 2007). Além disso, há também a possibilidade de venda dos serviços de sequestro de carbono, gerando os chamados "créditos de carbono" (BLEY JÚNIOR et al., 2009).
O processo anaeróbio de degradação da matéria orgânica contida nos resíduos permite também a redução das demandas química e bioquímica de oxigênio e de sólidos (ORRICO JÚNIOR et al., 2009). Além disso, reduz as emissões de odores, amônia, metano e óxido nitroso (ANGONESE et al., 2007), bem como minimiza a população de microrganismos patogênicos dos materiais tratados devido às elevadas temperaturas que são atingidas no processo (LUSTE \& LUOSTARINEN, 2010).

A tecnologia de digestão ou biodigestão anaeróbia é conhecida há séculos em todo o mundo, mas, só recentemente, o estudo e aplicação desta tecnologia têm despertado o interesse de diversos setores da sociedade (WU et al., 2010), em virtude dos benefícios econômicos e sociais, da busca por fontes renováveis de energia e das legislações ambientais (CHAE et al., 2008).

Contudo, conforme relataram Esperancini et al. (2007), ainda são escassos os estudos com ênfase nos aspectos econômicos da implantação de biodigestores, principalmente, em pequenas escalas de produção. Portanto, para a criação de sistemas anaeróbios de tratamento de resíduos da suinocultura, faz-se necessário analisar a execução do projeto, a fim de permitir a construção de instalações mais econômicas, bem como a recuperação dos investimentos de forma mais rápida (CERVI et al., 2010).

Em face do exposto, o objetivo do presente trabalho foi desenvolver uma análise econômica de um sistema de tratamento de resíduos da suinocultura contendo biodigestores tubulares, bem como descrever a simulação de um cenário a partir da venda de energia elétrica para as concessionárias de distribuição.

\section{MATERIAL E MÉTODOS}

O estudo foi desenvolvido na Granja Niterói, que possui sistema de produção de suínos de ciclo completo, ou seja, unidade de produção que abrange animais do nascimento até o abate, localizada no município de Lavras, estado de Minas Gerais, situada à latitude de $21^{\circ} 11^{\prime} 37^{\prime \prime}$ Sul e longitude de $45^{\circ} 25^{\prime} 41^{\prime}$ " Oeste, com altitude média de $812 \mathrm{~m}$. De acordo com a classificação de Köppen, o clima da região é Cwa, ou seja, temperado chuvoso 
(mesotérmico) com inverno seco e verão chuvoso, subtropical e temperatura média do mês mais quente de $22,1^{\circ} \mathrm{C}$ (DANTAS et al., 2007).

As edificações suinícolas que compõem o sistema de produção totalizam $4.514 \mathrm{~m}^{2}$ de área interna, onde são alojados, em média, 3.600 animais. As instalações são compostas por 13 galpões de alvenaria, com cobertura em telhas de fibrocimento, suportadas por pilares de concreto armado, com estrutura de cobertura em tesouras metálicas e beirais de $0,90 \mathrm{~m}$. Os dejetos são manejados na forma líquida e conduzidos para o sistema de tratamento em canaletas externas às instalações.

O sistema de tratamento de dejetos da granja consiste em: um tanque de equalização dotado de conjunto motobomba helicoidal de $25 \mathrm{~m}^{3} \mathrm{~h}^{-1}$ de vazão e $15 \mathrm{cv}$ de potência, que propicia a elevação do efluente até uma caixa difusora de fluxo, que distribui os resíduos para dois biodigestores tubulares, localizados em um ponto mais alto do terreno. A caixa difusora de fluxo, construída em fibra de vidro, tem por objetivo garantir a uniformidade de distribuição dos dejetos para os dois biodigestores.

Os dois biodigestores, com $2,5 \mathrm{~m}$ de profundidade, $12 \mathrm{~m}$ de largura e $32 \mathrm{~m}$ de comprimento cada um, são cobertos com lona de policloreto de vinila (PVC) e possuem sistema para recirculação dos dejetos. As laterais e o fundo dos biodigestores são revestidos com lona de PVC.

O sistema de recirculação é composto por um tubo de PVC de $100 \mathrm{~mm}$, instalado no terço final de cada biodigestor, dotado de quatro orifícios de $100 \mathrm{~mm}$, espaçados entre si de $2,5 \mathrm{~m}$, que conduz os dejetos até um conjunto motobomba helicoidal de $8 \mathrm{~m}^{3} \mathrm{~h}^{-1}$ de vazão e $3 \mathrm{cv}$ de potência. Os dejetos são bombeados para o terço inicial do biodigestor e são distribuídos através de seis orifícios de $200 \mathrm{~mm}$.

Após um tempo de retenção hidráulica de 30 dias nos biodigestores, os dejetos são escoados por gravidade, através de tubos de PVC de $200 \mathrm{~mm}$, para uma lagoa de polimento a fim de serem posteriormente utilizados como biofertilizante de pastagens e culturas anuais.

Foram levantados todos os valores nominais junto à administração da granja Niterói (custo, investimento e receita), no ano de 2011 e atualizados para 2018, conforme metodologia preconizada por Gonçalves et al. (2017a), Gonçalves et al. (2017b) e Casarotto Filho \& Kopittke (2010).
Com base nas informações contidas em Gonçalves et al. (2017a), Gonçalves et al. (2017b) e Casarotto Filho \& Kopittke (2010), foram analisados os indicadores de rentabilidade do sistema: valor presente líquido (VPL); taxa interna de retorno (TIR); relação benefício custo (RBC) e período de recuperação do capital simples e econômico (PRC e PRCe, respectivamente). Para o cálculo desses indicadores, foi adotado um horizonte de 10 anos e uma taxa de juros correspondente ao custo de oportunidade do capital aplicado em conta poupança de $6 \%$ a.a. (ao ano), de acordo com os procedimentos adotados por Junges et al. (2009) e Lopes et al. (2011), para ser empregado como fator de desconto dos fluxos de benefícios e custos.

Para propriedades rurais, a tarifa praticada pela Companhia Energética do Estado de Minas Gerais (CEMIG) é de $\mathrm{R} \$ 0,5079 \mathrm{kwh}^{-1}$, incluindo impostos e tarifas, valor auferido nas contas de energia elétrica (CEMIG, 2018).

A taxa mínima de atratividade utilizada também foi de $6 \%$ a.a, correspondente às aplicações em conta poupança. Para estimar a depreciação dos bens, foi adotado o método linear de depreciação, que equivale à perda de valor de determinado bem, seja por deterioração ou obsolescência. $\mathrm{O}$ valor de sucata foi considerado nulo pelo fato do objeto de estudo ser uma benfeitoria (CASAROTTO FILHO \& KOPITTKE, 2010).

O consumo anual de energia elétrica foi estimado com base na potência nominal dos motores, em $\mathrm{kWh}$ de trabalho, a um custo conforme valor de mercado aplicado no meio rural. Além disso, foi computado o consumo anual de mão-de-obra, em dias-homem (dh), nas operações de manejo do sistema, considerando o valor da diária sobre 1,42 salários-mínimos, tendo por base o salário do trabalhador mais acréscimo de $42 \%$, referente aos encargos sociais praticados contabilmente nos empreendimentos rurais.

Os benefícios diretos (BD) são provenientes da produção de efluente tratado ou esterco líquido estabilizado anaerobiamente (biofertilizante), utilizados para fertirrigação do solo. $\mathrm{O}$ valor anual dessa produção foi estimado com base na equivalência do esterco líquido (biofertilizante) em corretivos e fertilizantes. $\mathrm{O}$ valor da matéria orgânica foi estimado, atribuindo a esta o valor de mercado do adubo nitrogenado uréia (45\%).

Os benefícios indiretos (BI) são decorrentes 
da existência do projeto, que são caracterizados, consequentemente, pelo saneamento ambiental, de ordem econômica e sócio-econômica.

\section{RESULTADOS E DISCUSSÃO}

Os investimentos realizados para a montagem do sistema de tratamento de resíduos (efluentes), biodigestor e grupo moto gerador de energia estão relacionados na Tabela 1 .

Em uma unidade de terminação, com capacidade para 15 mil leitões, localizada no município de Toledo, estado do Paraná, Junges et al. (2009) estimaram um investimento de $\mathrm{R} \$ 365.052,91$, valor equivalente a $\mathrm{R} \$ 550.463,30$ no ano de 2018 , para a instalação de um sistema de tratamento de dejetos utilizando biodigestor tubular e conjunto grupo gerador, com capacidade superior a $288 \%$ em relação à granja estudada.

Considerando ainda as informações obtidas no mesmo trabalho, Junges et al. (2009) também estimaram os custos de instalação de um sistema de tratamento de dejetos, que utiliza biodigestores e conjunto grupo gerador, em $\mathrm{R} \$ 163.120,50$, valor equivalente a $245.969,40$ no ano de 2018 , ou seja, 20\% maior que a Granja Niterói. Contudo, é importante considerar que os resultados da pesquisa de Junges et al. (2009), que embasaram a comparação no presente trabalho, são provenientes de outra unidade de produção que trabalha com ciclo completo, composta por 450 matrizes, 15 reprodutores que reproduzem 11.000 leitões por ano e de onde também se realiza a terminação de 1.400 leitões.

A variação entre os resultados obtidos na literatura e os contabilizados no presente estudo pode ser justificada pela variação dos valores econômicos, devido a incidência da inflação acumulada nos últimos cinco anos (GONÇALVES et al., 2017a; GONÇALVES et al., 2017b; CASAROTTO FILHO \& KOPITTKE, 2010), além do posicionamento geográfico das unidades de produção de suínos, que contribui fortemente para variação entre valores de serviços, materiais e equipamentos. No presente estudo, também foi necessário montar uma estação elevatória de dejetos na granja, dada a topografia e o espaço físico disponível para a construção do sistema

Tabela 1. Investimentos realizados para a montagem do sistema de tratamento de efluentes, biodigestor e grupo moto gerador de energia.

\begin{tabular}{ccc}
\hline Discriminação dos investimentos* & Valor R\$ & $\%$ \\
\hline Terraplenagem & $96.957,97$ & 21,81 \\
Lona biodigestor & $143.250,50$ & 32,22 \\
Lona lagoa facultativa e tanque equalização & $46.744,90$ & 10,52 \\
Obra civil biodigestor & $41.618,04$ & 9,36 \\
Ferragem de ancoragem da lona biodigestor & 7916,47 & 1,78 \\
Construção abrigo para o conjunto grupo gerador & $2.714,22$ & 0,61 \\
Conjunto grupo gerador & $75.395,00$ & 16,96 \\
Tubulação PVC condução de dejeto & $3.980,85$ & 0,9 \\
Tubulação PVC condução de biogás & $1.260,60$ & 0,28 \\
Filtro de gás sulfídrico & 573,00 & 0,13 \\
Conjunto motobomba para recalque do dejeto & $13.571,10$ & 3,05 \\
Conjunto motobomba para recirculação do dejeto & $10.555,30$ & 2,37 \\
\hline Total & $444.537,97$ & 100 \\
\hline
\end{tabular}

*Ano de observação 2011, cujos valores foram atualizados para o ano de 2018. 
de tratamento. Também impactou nos custos do presente sistema a utilização de lagoa de polimento para tratamento final dos resíduos, visando um efluente mais depurado.

Observou-se também que por característica intrínseca da topografia da propriedade em estudo, o custo da terraplenagem foi elevado, totalizando R $\$ 96.957,97$. Por outro lado, Junges et al. (2009) estimaram custo de $\mathrm{R} \$ 56546,25$ para execução da terraplenagem em unidade de terminação para 15 mil leitões e $\mathrm{R} \$ 67.855,55$ para um sistema de produção com um plantel de 450 matrizes suínas.

As receitas auferidas à granja pelo sistema implementado são a venda de biofertilizante, uma vez que a propriedade não possui área para plantio próprio, e a independência energética. A receita anual referente à venda de biofertilizante foi estimada em $\mathrm{R} \$ 22.813,29$, atribuindo a este o valor de mercado do adubo nitrogenado uréia (45\%) a partir da quantificação do nitrogênio disponível no biofertilizante produzido em um ano pela granja. $\mathrm{E}$ o consumo energético, por toda a granja, totalizou um custo anual de energia elétrica de $\mathrm{R} \$ 63.333,05$.

Os custos foram divididos em custos fixos (CF), custos referentes à manutenção do biodigestor (Tabela 2) e custos variáveis $(\mathrm{CV})$ referentes à manutenção do motogerador (Tabela 3).

Tabela 2. Custo de depreciação dos bens utilizados na construção do sistema de tratamento de efluente da granja em estudo.

\begin{tabular}{cccc}
\hline Descrição & Valor Inicial (R\$) & Valor Útil (anos) & Depreciação anual \\
\hline Terraplenagem & $96.957,97$ & 25 & $3.878,32$ \\
Lona Biodigestor & $143.250,50$ & 10 & $14.325,05$ \\
Lona Lagoa facultativa e tanque equalização & $46.744,90$ & 10 & $4.674,49$ \\
Obra civil biodigestor & $41.618,04$ & 25 & $1.664,72$ \\
Construção abrigo para o conjunto grupo gerador & $2.714,22$ & 25 & 108,57 \\
Conjunto grupo gerador & $75.395,00$ & 10 & $7.539,50$ \\
Tubulação PVC condução de dejeto & $3.980,85$ & 10 & 398,09 \\
Tubulação PVC condução de biogás & $1.260,60$ & 10 & 126,06 \\
Filtro de limalha de ferro & 573,00 & 10 & 57,30 \\
Conjunto motobomba para recalque do dejeto & $13.571,10$ & 10 & $1.357,11$ \\
Conjunto motobomba para recirculação do dejeto & $10.555,30$ & 10 & $1.055,53$ \\
\hline Total & $436.621,48$ & - & $35.184,73$ \\
\hline
\end{tabular}

Tabela 3. Custo de operação e manutenção preventiva do grupo motogerador a biogás utilizado na granja em estudo.

\begin{tabular}{cccc}
\hline Componente & Intervalos (horas) & $\begin{array}{c}\text { Custo de operação e } \\
\text { manutenção (R\$) }\end{array}$ & $\begin{array}{c}\text { Custo anual de operação e } \\
\text { manutenção (R\$) }\end{array}$ \\
\hline Óleo lubrificante & 100 & 49,76 & $4.39,04$ \\
Filtro de óleo & 400 & 84,44 & $1.849,29$ \\
Filtro gás sulfídrico & 200 & 150,79 & $6.604,60$ \\
Filtro de ar & 2000 & 144,76 & 723,79 \\
Correia dentada e esticador & 1000 & 361,90 & $3.257,06$ \\
\hline Total & & & $16.793,78$ \\
\hline
\end{tabular}


A operação do sistema de tratamento de dejetos é diária e exige a presença de um funcionário responsável pelo acionamento dos motores, limpeza e zelo das instalações. Assim, o tempo de operação foi estimado em $450 \mathrm{~h}$ ano ${ }^{-1}$ e os gastos com salários de $\mathrm{R} \$ 9,73 \mathrm{~h}^{-1}$. Dessa forma, o custo da mão-de-obra necessária para a manutenção, tempo de operação exigido em função do salário, foi de $\mathrm{R} \$ 4.376,68 \mathrm{ano}^{-1}$.

Os gastos totais com manutenção e operação do biodigestor e grupo gerador foram estimados em $\mathrm{R} \$ 21.656,76$, representando $4,32 \%$ do investimento inicial para a implantação do sistema, sendo que este valor é bastante próximo ao obtido no trabalho de Coldebela et al. (2006) que adotaram $4 \%$ do investimento total para estimar os gastos com operação e mão-de-obra utilizados na manutenção de um sistema composto por um biodigestor tubular para tratamento de dejetos bovinos e um conjunto grupo gerador.

O fluxo de caixa do projeto foi estimado considerando-se um período de 10 anos, que representa a vida útil do grupo gerador de energia elétrica e as lonas utilizadas no sistema de tratamento de dejetos, os bens de maiores valores, aos quais são descontados uma taxa de $10 \%$ ao ano. O fluxo de caixa foi considerado como o fator de recuperação do capital inicial.

Dessa maneira, a receita operacional foi interpretada como a economia em função do tempo de operação da planta da tarifa de energia elétrica paga, bem como a venda de biofertilizante.

O demonstrativo do fluxo de caixa do projeto, com projeções de 10 anos, permitiu elaborar os indicadores econômicos, conforme proposto por Casarotto Filho \& Kopittke (2010), para apresentação dos resultados referentes à granja em estudo (Tabela 4).

A receita anual correspondente à venda de biofertilizantes e redução da taxa de energia elétrica, quando somados, totalizam R $\$ 86.146,34$.
Após deduzir os custos de operações, obteve-se um saldo do caixa anual de $\mathrm{R} \$ 20.590,36$, que somado à depreciação anual torna disponível em caixa $\mathrm{R} \$ 56.085,12$, já no primeiro ano de operação do sistema de tratamento de efluentes.

$\mathrm{O}$ valor presente líquido (VPL) foi estimado em $\mathrm{R} \$ 17.210,51$. Quando o VPL é maior do que zero, indica que a taxa de retorno do investimento TIR é maior do que a taxa mínima de atratividade (TMA) estipulada, neste caso $6 \%$ a.a. (CASAROTTO FILHO \& KOPITTKE, 2010).

O percentual determinado para TIR foi de $7 \%$ a.a, o que corrobora com a justificativa do VPL positivo. Esta taxa foi $1 \%$ superior à taxa de atratividade mínima, ou seja, o projeto é economicamente viável uma vez que o retorno econômico é mais atrativo do que aplicar o dinheiro em conta poupança (CASAROTTO FILHO \& KOPITTKE, 2010).

Apesar dos indicadores VPL e TIR serem otimistas com relação à implantação do projeto, em se tratando de sistemas para tratamento de águas residuárias, sua instalação faz-se por força de lei. A resolução do CONAMA n ${ }^{\circ} 430$ de 13 de maio de 2011 (BRASIL, 2011), que alterou e complementou a Resolução do CONAMA n³57/2005 (BRASIL, 2005), classifica os corpos d'água, estabelece os padrões de qualidade das águas e estabelece os padrões de lançamento de efluentes (BRASIL, 2005). Portanto, é importante que os projetos ambientais sejam elaborados, fundamentados na legislação. Entretanto, torna-se muito interessante a adoção de sistemas que também possibilitem a geração de receitas para o empreendimento, fato que pode ser verificado pela análise da RBC.

A RBC estimada de 1,42 é considerada alta para este tipo de investimento, representando uma eficiência econômica de $42 \%$, ou seja, para cada unidade de real $(\mathrm{R} \$ 1,00)$ investida no projeto, obter-se-á um retorno líquido de $\mathrm{R} \$ 0,42$, tornando assim a RBC um critério prático de tomada de

Tabela 4. Indicadores econômicos do sistema de tratamento de efluentes da granja em estudo.

\begin{tabular}{cccccc}
\hline Receita operacional & $\mathrm{RBC}^{1}$ & $\mathrm{VPL}^{2}$ & $\mathrm{PRC}^{3}$ & $\mathrm{PRCe}^{4}$ & $\mathrm{TIR}^{5}$ \\
& & $\mathrm{R} \$$ & $\mathrm{Anos}$ & $\mathrm{Anos}$ & $\%$ \\
$86.146,34$ & 1,42 & $17.210,51$ & 7 & 8 & 7 \\
\hline
\end{tabular}

${ }^{1} \mathrm{RBC}=$ relação beneficio custo; ${ }^{2} \mathrm{VPL}=$ valor presente líquido; ${ }^{3} \mathrm{PRC}=$ período de recuperação do capital simples e econômico; ${ }^{4} \mathrm{PRCe}=$ período de recuperação do capital econômico; ${ }^{5}$ TIR taxa interna de retorno. 
decisão, quando é importante o conhecimento dos efeitos a longo prazo. Nogueira (2001) aponta que para um projeto ser viável economicamente, a $\mathrm{RBC}$, em principio, deverá ser maior do que 1 .

O período de recuperação do capital investido simples (PRC), definido como período de tempo em que o custo do investimento é coberto pelas entradas líquidas de caixa, foi de 7 anos. Já o PRCe é mais conservador e confiável, pois, leva em consideração a desvalorização monetária no decorrer do tempo e, para esta planta, foi estimado em 8 anos. Cassarotto Filho \& Kopittke (2010) destacaram que para viabilidade econômica de um projeto é necessário que o somatório do fluxo líquido de caixa para o período de PRC simples e o PRCe sejam, no mínimo, igual ao investimento inicial.

Junges et al. (2009), avaliando dois sistemas intensivos de produção de suínos, obtiveram, para uma das granjas avaliadas, resultados inferiores em relação aos encontrados no presente trabalho, sendo TIR de 5,20\%, VPL de R $\$ 14.182,20$ negativo, valor equivalente a R $\$ 21.385,34 \mathrm{em} \mathrm{2018,} \mathrm{PRC}$ negativo para uma TMA de $8,0 \%$.

Os indicadores econômicos determinados para a granja estudada indicam que o investimento apresenta viabilidade econômica de implantação do sistema, haja vista que a TIR foi superior à TMA e o VPL foi positivo. Apesar do sistema avaliado ter apresentado viabilidade econômica, ressalta-se que é possível buscar alternativas que tornem os sistemas de tratamento de efluentes economicamente ainda mais atrativos, seja com a venda de créditos de carbono ou através da produção/venda de energia elétrica à concessionária local (BLEY JÚNIOR et al., 2009).

Com intuito de avaliar os impactos da geração distribuída de energia sobre a viabilidade econômica, foi construído um cenário alternativo baseado na venda de energia elétrica à CEMIG.

A geração distribuída de energia é o modo de geração de energia elétrica conectada em sincronia com a rede de distribuição, que viabiliza a geração por micro-centrais, possibilitando a descentralização do sistema. A geração distribuída pode servir para qualquer fonte renovável de energia elétrica, como eólica, solar, hídrica e geotérmica, e no caso da geração de biogás, além dos efeitos energéticos, ainda produz efeitos ambientais, econômicos e sociais (BLEY JÚNIOR et al., 2009).

$\mathrm{O}$ valor pago aos suinocultores por ocasião da venda dos excedentes de energia elétrica (em $\mathrm{kWh}$ ), pelas concessionárias que já trabalham com o sistema de geração distribuída de eletricidade, é regulado pela Agência Nacional de Energia Elétrica (ANEEL) e está baseado no Valor Anual de Referência (VR), que regula o repasse das tarifas aos consumidores finais, dado o custo de aquisição de eletricidade (ANEEL, 2018).

Atualmente, o VR é de R $\$ 213,70$ por megawatt (ANEEL, 2018). Assumindo-se que este valor será aplicado pela CEMIG para compra de energia de fontes geradoras distribuídas, pode-se avaliar a variação dos indicadores econômicos diante da receita adicional pela venda de energia elétrica.

$O$ gerador instalado na granja em estudo possui potência de $50 \mathrm{kVA}$, com fator de potência $\phi=0,90$. Assim, a granja possui potencial anual de geração energética de $394.200 \mathrm{kWh}$, dos quais a mesma utiliza $140.058 \mathrm{kWh}$. O consumo energético anual dessa granja corresponde a $35,5 \%$ da sua capacidade de geração energética, sendo que o excedente poderia ser vendido.

De acordo com o Centro para Conservação de Energia (CCE, 2000), o poder calorífico inferior do biogás é de $6,5 \mathrm{kWh} \mathrm{m}^{-3} \mathrm{e}$ a eficiência de conversão do biogás em eletricidade com grupos geradores é de aproximadamente $25 \%$. Portanto, para a geração de $394.200 \mathrm{kWh}^{2}$ ano $^{-1}$, seria necessário ter disponível $1.576 .800 \mathrm{kWh}^{-1} \mathrm{no}^{-1}$ advindo do biogás, o que corresponderia a $242.584,61 \mathrm{~m}^{3}$ de biogás ano $^{-1}$.

A partir da metodologia proposta por Souza et al. (2008), pôde-se estimar que a produção volumétrica anual de metano é de $200.870 \mathrm{~m}^{3}$, o que corresponde a $309.031 \mathrm{~m}^{3}$ de biogás. Portanto, a referida propriedade possui potencial para ser uma micro-central de energia distribuída para abastecimento da CEMIG.

Desse modo, foi estimada a venda de $64,5 \%$ de toda energia que poderia ser gerada pela granja, obtendo uma receita anual de $\mathrm{R} \$ 54.756,24$. Essa nova renda, caso viesse a ser efetivada, corresponderia a $63,54 \%$ do total da receita advinda do sistema de tratamento, evidenciando que novas políticas públicas devem ser adotadas para garantir a viabilidade econômica de sistemas de tratamento de efluentes (BLEY JÚNIOR et al., 2009), como pode ser observado na Tabela 5 . 
AVALIAÇÃO ECONÔMICA DE UM SISTEMA DE TRAMENTO DE RESÍDUOS DA SUINOCULTURA CONTENDO BIODIGESTORES...

Tabela 5. Simulação dos indicadores econômicos com e sem venda de energia elétrica.

\begin{tabular}{ccccccc}
\hline $\begin{array}{c}\text { Geração } \\
\begin{array}{c}\text { Distribuída de } \\
\text { Energia }\end{array}\end{array}$ & $\begin{array}{c}\text { Receita } \\
\text { operacional }\end{array}$ & $\mathrm{RBC}^{1}$ & $\begin{array}{c}\mathrm{VPL}^{2} \\
\mathrm{R} \$\end{array}$ & $\begin{array}{c}\mathrm{PRC}^{3} \\
\text { Anos }\end{array}$ & $\mathrm{PRCe}^{4}$ Anos & $\mathrm{TIR}^{5} \%$ \\
\hline Não & $86.146,34$ & 1,42 & $17.210,51$ & 7,00 & 8 & 7 \\
Sim & $140.887,50$ & 2,25 & $397.304,53$ & 4,08 & 4 & 22 \\
\hline
\end{tabular}

${ }^{1} \mathrm{RBC}=$ relação beneficio custo; ${ }^{2} \mathrm{VPL}=$ valor presente líquido; ${ }^{3} \mathrm{PRC}=$ periodo de recuperação do capital simples e econômico; ${ }^{4} \mathrm{PRCe}=$ período de recuperação do capital econômico; ${ }^{5}$ TIR taxa interna de retorno.

Os dados da Tabela 5 mostram que, com a receita advinda da venda de energia elétrica, haveria incremento significativo nos indicadores econômicos, uma vez que a receita operacional foi acrescida em 163,54\%; a relação custo benefício teve aumento de $158,45 \%$; o valor presente líquido aumentou em 23 vezes, atingindo o valor total de $\mathrm{R} \$ 397.304,55$; os períodos de recuperação de capital reduziram quase que pela metade o tempo de reembolso e a taxa interna de retorno saltou de $5 \%$ para $22 \%$, valor superior em $366,6 \%$ à taxa mínima de atratividade.

Com base nas estimativas verificadas no cenário proposto, é possível afirmar que a granja estudada possui potencial para aumentar seus ganhos através da venda de energia elétrica e com investimento adequado no sistema de geração e distribuição de energia à rede pública, para garantir o fornecimento de energia com qualidade. Por outro lado, foi constatada a relevância da necessidade de participação das companhias geradoras e distribuidoras de energia elétrica, nesse caso a CEMIG, para promover o aproveitamento total de todo o potencial energético da propriedade, como acontece, por exemplo, com a Companhia Paranaense de Energia (COPEL), no estado do Paraná (BLEY JÚNIOR et al., 2009).

Portanto, numa visão holística, tem-se que o processo de biodigestão anaeróbia de dejetos de suínos promove o saneamento rural (ANGONESE et al., 2007), além de gerar dois produtos e um serviço, ou seja, o biogás e o biofertilizante, e a venda dos serviços de sequestro de carbono, gerando os chamados créditos de carbono (BLEY JÚNIOR et al., 2009).

Como todo produto, o biogás também constitui e sustenta uma cadeia de demandas e suprimentos relativamente complexa, ou seja, o biogás é centro gerador e mantenedor de economias que se constituem em seu entorno. A produção de biogás demanda, consome e gera resultados econômicos e, como se encontra pulverizada nos ambientes rurais, favorecê-la significa também distribuir localmente os resultados econômicos produzidos por esta economia. São resultados diretos a geração de energias elétrica, térmica e automotiva, com redução de emissões de gases do efeito estufa e, por isso, a obtenção de créditos de carbono e também resultados econômicos indiretos, como as demandas por serviços de planejamento, implantação, operação e manutenção dos processos que produzem o biogás e das energias que com ele podem ser geradas (BLEY JÚNIOR et al., 2009).

$\mathrm{O}$ outro produto do processo de biodigestão anaeróbia, o biofertilizante, contém macro e micronutrientes interessantes sob o ponto de vista do uso agrícola, que podem ser utilizados como fonte de nutrientes às culturas e aos solos, possibilitando uma reciclagem desses nutrientes nas próprias unidades de produção, o que contribui para maior sustentabilidade e balanço energético dos sistemas de produção (ANGONESE et al., 2007).

\section{CONCLUSÃO}

- A avaliação econômica do sistema permitiu concluir que o projeto é economicamente atrativo, pois o cenário aponta para fluxo líquido de caixa positivo e indicadores econômicos atrativos.

- A simulação da venda de excedentes de eletricidade para a concessionária local contribui para a melhoria dos indicadores econômicos de investimento, além de criar um cenário mais favorável à proteção ambiental.

- Enfim, os produtos e o serviço provenientes 
da energia do biogás promovem a geração de impactos positivos nos âmbitos ambiental, social, agronômico e, sobretudo, econômico.

\section{REFERÊNCIAS BIBLIOGRÁFICAS}

ANEEL. AGÊNCIA NACIONAL DE ENERGIA ELÉTRICA (2010). Nota técnica $\mathbf{n}^{0} \mathbf{0 0 4 3 / 2 0 1 0 -}$ SRD/ANEEL. Disponível em: <http://www.aneel. gov.br/aplicacoes/consulta_publica/documentos/ Nota $\% 20 T \% C 3 \% A 9 c n i c a+0043$ GD_SRD.pdf $>$. Acesso em: 25 de maio de 2012.

ANGONESE, A.R.; CAMPOS, A.T.; WELTER, R.A. Potencial de redução de emissão de equivalente de carbono de uma unidade suinícola com biodigestor. Engenharia Agrícola, Jaboticabal, v.27, n.3, p.648-657, 2007.

BLEY JUNIOR, C.; LIBÂNIO, J. C.; GALINKIN, M.; OLIVEIRA, M.M. Agroenergia da Biomassa Residual: perspectivas energéticas, socioeconômicas e ambientais. Foz do Iguaçu: Itaipu Binacional, 2009.

BRASIL. Conselho Nacional do Meio Ambiente. Resolução CONAMA No 430, de 13 de maio de 2011. Dispõe sobre as condições e padrões de lançamento de efluentes, complementa e altera a Resolução $N^{\circ}$ 357, de 17 de março de 2005, do Conselho Nacional do Meio Ambiente-CONAMA.

Diário Oficial da União, Poder Executivo, Brasília, 13 de maio de 2011.

BRASIL. Conselho Nacional do Meio Ambiente. Resolução CONAMA N ${ }^{\circ}$ 357, de 17 de março de 2005. Dispõe sobre a classificação dos corpos de água e diretrizes ambientais para o seu enquadramento, bem como estabelece as condições e padrões de lançamento de efluentes, e dá outras providências. Diário Oficial da União, Poder Executivo, Brasília, 18 de março de 2005.

CASAROTTO FILHO, N.; KOPITTKE, B.H. Análise de investimentos: matemática financeira, engenharia econômica, tomada de decisão, estratégia empresarial. Atlas, 2010.
CCE. Centro, para conservação e. energia. Guia técnico de biogás. Algés: JE92 Projectos de Marketing Ltda, 2000.

CEMIG. Companhia Energética do Estado de Minas Gerais. Disponível em: $<$ http://www.cemig. com.br>. Acesso em: 25 de maio de 2012.

CERVI, R.G.; ESPERANCINI, M.S.T.; BUENO, O.C. Viabilidade econômica da utilização do biogás produzido em granja suinícola para geração de energia elétrica. Engenharia Agrícola, Jaboticabal, v.30, n.5, p.831-844, 2010.

CHAE, K.J.; JANG, A.M.; YIM, S.K.; KIM, I.S. The effects of digestion temperature and temperature shock on the biogas yields from the mesophilic anaerobic digestion of swine manure. Bioresource Technology, Oxford, v.99, n.1, p.1-6, 2008.

COLDEBELLA, A. Viabilidade do uso do biogás da bovinocultura e suinocultura para geração de energia elétrica e irrigação em propriedades rurais. 2006. 73p. Dissertação (Mestrado em Engenharia Agrícola) - Universidade Estadual do Oeste do Paraná, Cascavel, 2006.

DANTAS,A.A.A.;CARVALHO,L.G.;FERREIRA, E. Classificação e tendências climáticas em Lavras, MG. Ciência e Agrotecnologia, Lavras, v. 31, n.6, p.1862-1866, 2007.

ESPERANCINI, M.S.T.; COLEN F.; BUENO O.C.; PIMENTEL A.E.B.; SIMON E.J. Viabilidade técnica e econômica da substituição de fontes convencionais de energia por biogás em assentamento rural do estado de São Paulo. Engenharia Agrícola, Jaboticabal, v.27, n.1, p.110-118, 2007

GONÇALVES, G.V.B.; VAZ, R.Z.; VAZ, F.N.; MENDONÇA, F.S.; FOUTOURAJÚNIOR, J.A.S.; CASTILHO, E.M. Análise de custos, receitas e ponto de equilíbrio dos sistemas de produção de bezerros no Rio Grande do Sul. Ciência Animal Brasileira, Goiânia, v.18, e-46329, p.1-17, 2017a. 
AVALIAÇÃO ECONÔMICA DE UM SISTEMA DE TRAMENTO DE RESÍDUOS DA SUINOCULTURA CONTENDO BIODIGESTORES...

GONÇALVES, J.C.; OLIVEIRA, A.D.; CARVALHO, S.P.C.; GOMIDE, L.R. Análise econômica da rotação florestal de povoamentos de eucalipto utilizando a simulação de Monte Carlo. Ciência Florestal, Santa Maria, v.27, n.4, p.13391347, $2017 \mathrm{~b}$.

HIGARASHI, M.M.; KUNZ, A.; MATTEI, R.M. Aplicação de adsorção para remover amônia de efluentes suinícolas pré-tratados. Química Nova, São Paulo, v.31, n.5, p.1156-1160, 2008.

JUNGES, D.M.; KLEINSCHMITT, S.C.; SHIKIDA, P.F.A.; SILVA, J.R. Análise econômico-financeira da implantação do sistema de biodigestores no Município de Toledo (PR). Revista de Economia, Curitiba, v.35, n.1, p.7-20, 2009.

KUNZ, A.; MIELE, M.; STEINMETZ, R. Advanced swine manure treatment and utilization in Brazil. Bioresource Technology, Oxford, v.100, n.22, p.5485-5489, 2009a.

KUNZ, A.; STEINMETZ, R.; RAMME, M.; COLDEBELLA, A. Effect of storage time on swine manure solid separation efficiency by screening. Bioresource Technology, Oxford, v.100, n.5, p.1815-1818, 2009b.

KUNZ, A.; HIGARASHI, M.M.; OLIVEIRA, P.A. Tecnologias de manejo e tratamento de dejetos de suínos estudadas no Brasil. Cadernos de Ciência \& Tecnologia, Brasília, v.22, n.3, p.651-665, 2005.

LOPES, M.A.; SANTOS, G.; RESENDE, M.C.; CARVALHO, F.M; CARDOSO, M.G. Estudo da rentabilidade de sistemas de produção de leite no município de Nazareno, MG. Ciência Animal Brasileira, Goiânia, v.12, n.1, p.58-69, 2011.
LUSTE, S.; LUOSTARINEN, S. Anaerobic codigestion of meat-processing by-products and sewage sludge-Effect of hygienization and organic loading rate. Bioresource Technology, Oxford, v.101, n.8, p.2657-2664, 2010.

NOGUEIRA, E. Análise de investimentos In: BATALHA, M.O. Gestão Agroindustrial. São Paulo: Atlas, v.388, p.23, 2001.

OLIVEIRA, P.A.V.; SILVA, A.P.; PERDOMO, C.C. Aspectos construtivos na produção de suínos visando aos aspectos ambientais de manejos dos dejetos. In: SEGANFREDO, M.A (ed.). Gestão ambiental na suinocultura. Brasília: Embrapa Informação Tecnológica. 2007, p.177216.

ORRICO JÚNIOR, M.A.P.; ORRICO, A.C.A.; LUCAS JÚNIOR. Biodigestão anaeróbia de dejetos de suínos com e sem separação da fração sólida em diferentes tempos de retenção hidráulica. Engenharia Agrícola, Jaboticabal, v.29, n.3, p.474-482, 2009.

SOUZA， C.D.F.; CARVALHO， C.D.C.S.; CAMPOS, J.A. MATOS, A.T.; FERREIRA, W.P.M. Caracterização de dejetos de suínos em fase de terminação. Revista Ceres, Viçosa, v.56, n.2, p.128-133, 2009.

SOUZA, C.F.; CAMPOS, J.A.; SANTOS, C.R. BRESSAN, W.S.; MOGAMI, C.A. Produção volumétrica de metano - dejetos de suínos. Ciência e Agrotecnologia, Lavras, v.32, n.1, p.219-224, 2008.

WU, X.; YAO, W.; ZHU, J.; MILLER, C. Biogas and $\mathrm{CH} 4$ productivity by co-digesting swine manure with three crop residues as an external carbon source. Bioresource technology, Oxford, v.101, n.11, p.4042-4047, 2010. 